\title{
Structure and morphology of laser assisted chemical vapour deposited TiC coatings
}

\author{
M.L.F. PARAMÊS and O. CONDE \\ Department of Physics, University of Lisbon, Campo Grande Ed. C1, 1700 Lisboa, Portugal
}

\begin{abstract}
Titanium carbide has been deposited on silica substrates by pyrolytic laser chemical vapour deposition (LCVD) using a $\mathrm{cw}_{\mathrm{CO}}$ laser and a reactive atmosphere consisting of $\mathrm{TiCl}_{4}$, $\mathrm{CH}_{4}$ and $\mathrm{H}_{2}$. The partial pressures of the gaseous components were kept constant in all the experiments at 7,21 and 130 torr, respectively, while the laser power density and the interaction time were varied in the ranges $90-190 \mathrm{~W} . \mathrm{cm}^{-2}$ and $15-40 \mathrm{~s}$. The films were analyzed by X-ray diffraction (XRD), scanning electron microscopy (SEM) and stylus profilometry. In the range of the deposition parameters investigated, it is shown that preferentially $(200)$ oriented films have been produced. From the profilometric analyses, an apparent activation energy of about $86 \mathrm{~kJ} /$ mole for the kinetics of film deposition has been deduced.
\end{abstract}

\section{1.- Introduction}

Titanium carbide ( $\mathrm{TiC}$ ) coatings are well known for combining a number of special properties which have made them of particular interest for a wide variety of applications. TiC exhibits very high melting point and thermal stability, high hardness and excellent wear resistance, low coefficient of friction, high electrical and thermal conductivities [1]. Despite the fact that their major field of application is as wear resistant coatings for cutting tools and inserts, they have also been used as thermal barrier coatings in fusion reactors [2] and as a diffusion barrier in semiconductor technology [3].

Thin films of titanium carbide have been grown from the vapour phase using several techniques, either chemical or physical [4]. The use of a laser as the heat sourçe for the chemical vapour deposition of materials (thermal LCVD) was first reported in 1972 [5]. Ever since, LCVD has been extensively studied and used for the deposition of various metals, semiconductors and insulators, mainly for microelectronics applications [6].

Results on the LCVD of TiC on different substrate materials, by employing different types of lasers, were previously published in the literature by Allen and co-workers [7,8], and more recently by Umezawa et al. [9] and Westberg et al. [10]. In this work, we used a $\mathrm{CO}_{2}$ laser to thermally drive the following chemical reaction:

$$
\mathrm{TiCl}_{4}(\mathrm{~g})+\mathrm{CH}_{4}(\mathrm{~g})--->\mathrm{TiC}(\mathrm{s})+4 \mathrm{HCl}(\mathrm{g}),
$$

on fused silica substrates, yielding the formation of the TiC solid films. Due to the increase interest in the use of silica devices in waveguide optics, the protection of such devices became a more and more relevant 
subject. TiC may be considered a good candidate for the protection of those devices against, e.g., contamination by hydroxyl groups. Nevertheless, coating of silica by LCVD TiC is very little known [8].

\section{2.- Experimental Procedure}

A schematic diagram of the experimental apparatus used for the deposition of titanium carbide films is shown in figure 1 . Since this system was firstly used for depositing titanium nitride, a general description can already be found in reference [11]. Here, we focus mainly on the particularities which have been introduced in order to meet the new coating/substrate needs.

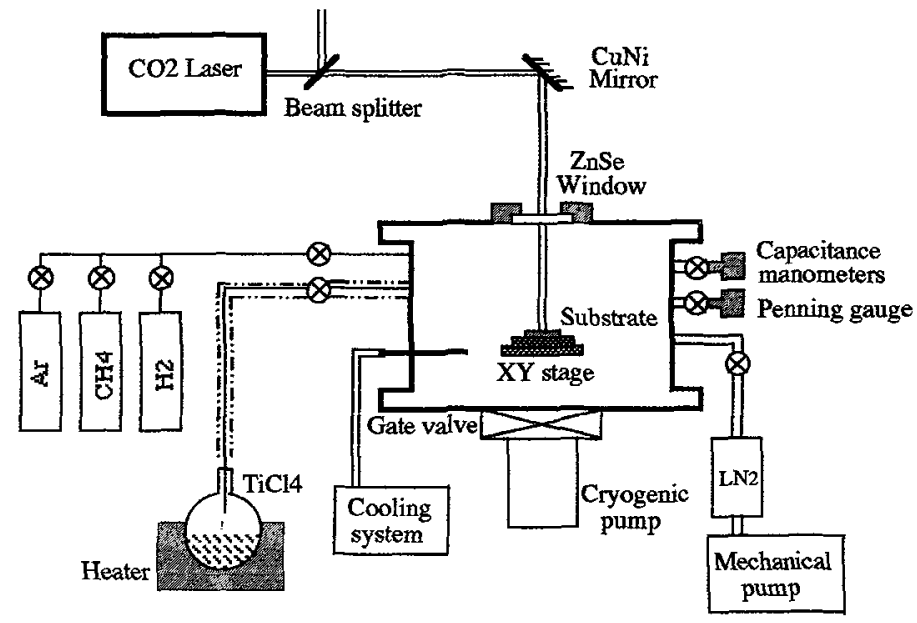

Fig. 1. - Laser chemical vapour deposition system

The $\mathrm{CO}_{2}$ laser was operated in continuous wave $\mathrm{TEM}_{00}$ mode at a wavelength of $10.6 \mu \mathrm{m}$. The laser beam was passed through a $\mathrm{ZnSe}$ beam-splitter $(\mathrm{R}=\mathrm{T}=50 \%)$ before impinging on the substrate at perpendicular incidence. The reflected beam was received in a water-cooled beam dumper or in a power meter. Because fused silica substrates, which absorb $\sim 84 \%$ of the laser infrared radiation [12], were employed throughout the experiments, no focusing lens was used. The spot diameter of the unfocused beam was $13 \mathrm{~mm}$ at the substrate surface.

The deposition reactor is a stainless steel chamber provided with a $\mathrm{ZnSe}$ window for the transmission of the $\mathrm{CO}_{2}$ laser beam and operating in the static fill mode. Before the introduction of the reaction gas mixture, consisting of $\mathrm{TiCl}_{4}, \mathrm{CH}_{4}$ and $\mathrm{H}_{2}$, the reaction chamber was always evacuated down to a base pressure less than $5 \times 10^{-6}$ torr. The partial pressures of the reactants were measured sequentially to be 7 , 21 and 130 torr for $\mathrm{TiCl}_{4}, \mathrm{CH}_{4}$ and $\mathrm{H}_{2}$, respectively, and were kept constant at these values in most experiments. The substrates used were fused silica $15 \times 15$ or $25 \times 25 \mathrm{~mm}^{2}$ plates. They were ultrasonically cleaned in acetone and ethanol prior to insertion in the reactor.

The titanium carbide films were grown with the substrates immobile under the laser beam for irradiation times varying from 15 to 40 seconds. The incident laser power took values in the range $135-250 \mathrm{~W}$, 
yielding laser power densities between 90 and $160 \mathrm{~W} \cdot \mathrm{cm}^{-2}$. When the experiments were carried out at higher values, either of the laser power or of the interaction time, melting of the coating layer/substrate was observed.

The as-deposited films were investigated by X-ray diffracton (XRD) using $\mathrm{CuK} \alpha$ radiation and conventional Bragg-Brentano geometry. Both the surface morphology and the fractured cross-section of the films were examined by scanning electron microscopy (SEM). In a few cases, we have carried out a qualitative chemical analysis of the Ti and Si elements across the deposits by wavelenght dispersive spectrometry (WDS). The topography of the films and the thickness measurements were performed by using a diamond stylus profilometer.

\section{3.- Results and Discussion}

The deposits were primarily identified by X-ray diffraction. A typical XRD spectrum from the asdeposited material is illustrated in Fig. 2. In addition to the main peaks from $\mathrm{TiC}$, which are labeled in the figure by the Miller indices of the diffracting planes, a number of low intensity lines can also be observed.

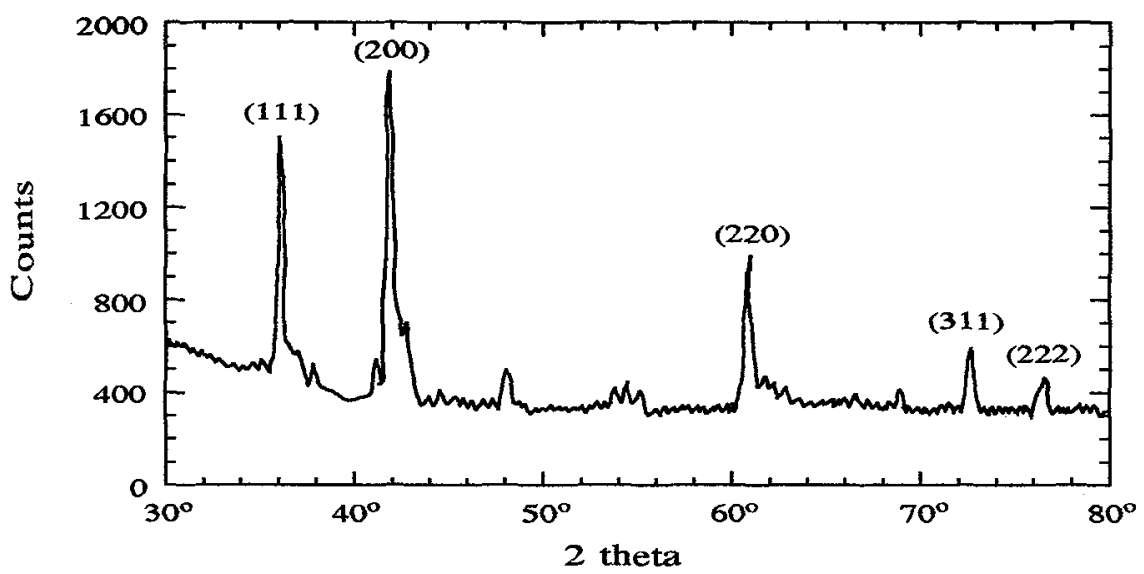

Fig. 2. - X-ray diffraction spectrum of a film grown at $250 \mathrm{~W}$ during 25 seconds. Labeled lines refer to TiC. Lower intensity lines are for various oxides.

The experimental intensity distribution pattern for the $\mathrm{TiC}$ follows qualitatively the general trends deduced for a polycrystalline TiC sample with the grains randomly oriented. However, an enhancement of the (200) peak was always encountered showing that the TiC films are preferentially $(200)$ oriented under the deposition conditions used in this work. This result was also found by Umezawa et al. [9] for the LCVD of TiC on stainless steel with a YAG laser when the ratio $\mathrm{H} 2 / \mathrm{CH} 4=6$, which is very close to our own ratio value of 6.2. The low intensity peaks were attributed to various titanium oxides, predominantly $\mathrm{TiO}_{2}$ (anatase) and less $\mathrm{Ti}_{3} \mathrm{O}_{5}$, which are actually visible at the outer rim of the titanium carbide spots where the deposition temperature is lower. The presence of Ti in this region was confirmed by WDS 
analysis. Furthermore, a colour analysis of the spots has still revealed that in most coatings a very narrow yellow-olive ring surrounds the metallic-grey central film of TiC. It is very likely that a very thin layer of $\beta$ $\mathrm{SiC}$ has formed as a result of the exposure of the silica substrate at high temperature to the $\mathrm{CH}_{4}$ and $\mathrm{H}_{2}$ gaseous reactants $[13,14]$. Because of the small amount of $\mathrm{SiC}$ material and also the lattice parameter of the silicon and titanium carbides are very close, it is difficult to detect the presence of B-SiC by XRD analysis. However, in some patterns there was some evidence of SiC peaks superposed on the shoulder of the $\mathrm{TiC}$ peaks. The formation of an interlayer of silicon carbide can be very beneficial in providing a graded variation of the coefficient of thermal expansion between the silica substrate and the TiC coating $\left(0.5 \times 10^{-6}\right.$ $\mathrm{K}^{-1}, 3.6 \times 10^{-6} \mathrm{~K}^{-1}$ and $7.6 \times 10^{-6} \mathrm{~K}^{-1}$, respectively for $\mathrm{SiO}_{2}, \mathrm{SiC}$ and $\mathrm{TiC}$ ), and thus reducing the appearance of fissures during the cooling of the system due to thermal stresses.
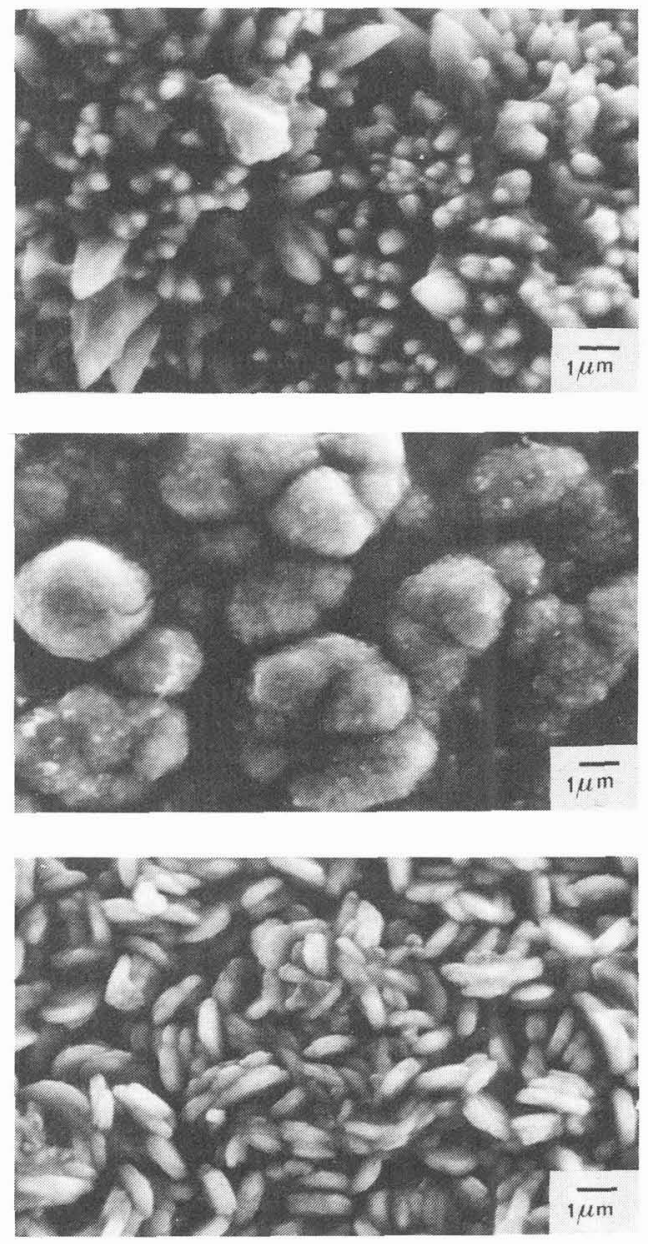

Fig. 3. - Scanning secondary electron micrographs of the surface of a TiC film grown at $175 \mathrm{~W}$ during 40 s. a) faceted crystallites, b) nodules, c) platelets.
Figure 3 shows SEM images from the surface of a TiC film grown at a laser power of $175 \mathrm{~W}$ for a constant irradiation time, $\mathrm{t}=40 \mathrm{~s}$. These micrographs illustrate sequential zones of the film from the centre (Fig. 3a) to the a) periphery (Fig. 3c). As it can be seen, the surface morphology and the microstructure change with distance from the spot centre owing to the strong dependence on the local induced temperature. For the deposition conditions used throughout this work, three types of microstructure related to $\mathrm{TiC}$ deposition were usually found: faceted

b) crystallites in the central region (Fig. 3a), which is the more extended one $(\sim 60-70 \%$ of spot diameter), surrounded by a nodular region (Fig. 3b) and another one consisting of platelets (Fig. 3c) at the edge. When the lowest values of laser power, between 135 and 200 $\mathrm{W}$, and interaction time (15 s) were employed, only two different microstructures, nodules c) and platelets, have been seen. The growth of crystallites in the highest temperature zone has also been reported by Umezawa et al. [9] for their YAG laser assisted TiC deposited films.

These various microstructures are the typical ones for conventional CVD of TiC coatings [15-18] which can be encountered for the different process conditions of temperature, gaseous reactants concentration, substrate 
material, etc. In particular, it has been described that titanium carbide platelets grow in a CVD process preferentially at lower deposition temperatures [18]. On the other hand, this microstructure is also visible out of the centre of TiN spots deposited by thermal LCVD with a $\mathrm{CO}_{2}$ laser [19].

We plotted in figure 4 the spatial variation of the thickness of the TiC layers deposited at the highest value of the incident laser power, $250 \mathrm{~W}$, for irradiation times ranging from 25 to $40 \mathrm{~s}$. This selection of the deposition parameters was made with the aim of illustrating a representative behaviour of the film

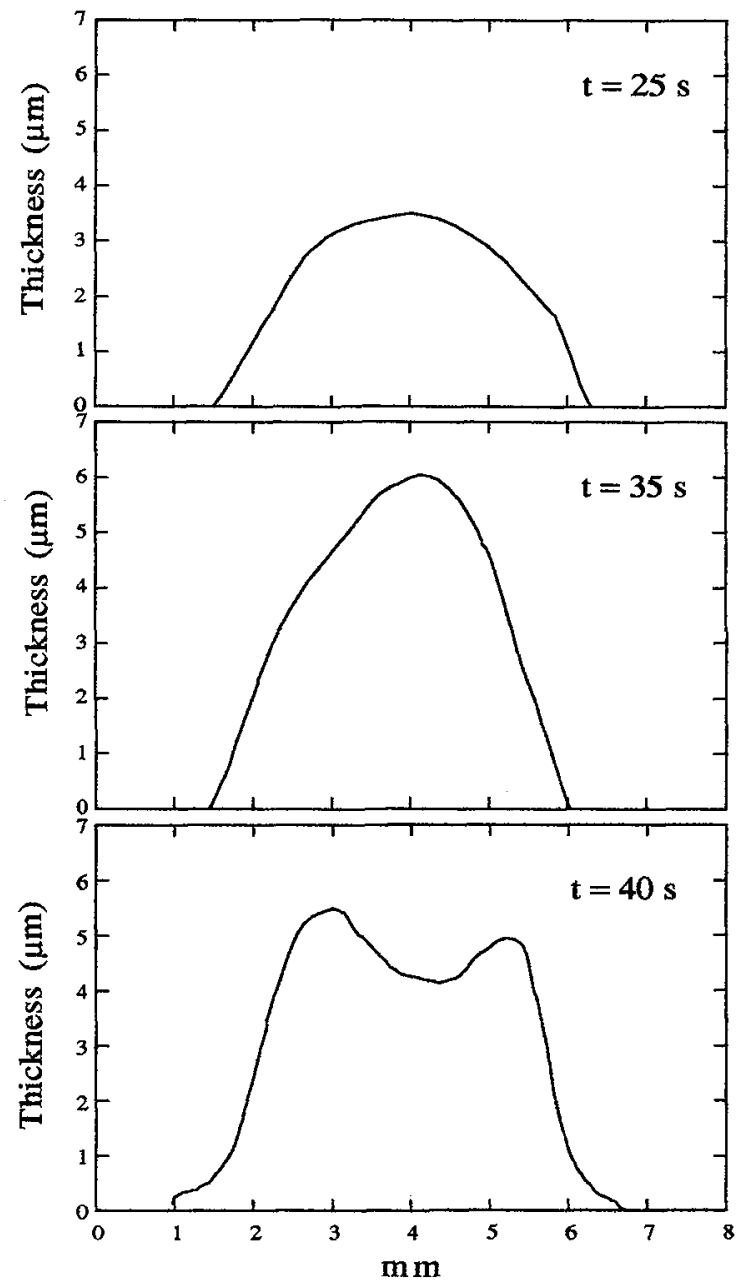

Fig. 4. - Spatial variation of the thickness of TiC films deposited at a constant laser power of $250 \mathrm{~W}$ for different irradiation times $t$. growth. In fact, while at constant irradiation time, an increase of the laser power affects the amount of $\mathrm{TiC}$ which is formed but not its distribution, for each value of the incident laser power a remarkable change on the temporal evolution is observed between 35 and $40 \mathrm{~s}$, the thickness profile changing from a gaussian type to a double-humped shape. The formation of volcano-like deposits at high laser induced deposition temperatures has often been reported in the literature $[8,20,21]$ and various models have been proposed [22-26] based on high chemical reaction rates, convection from the surface, low sticking probability, etc. In our case, since for each two molecules consumed in the reaction, four of hydrogen chloride are produced, there can be an accumulation of reaction products in the chemical reaction zone. This will increase the local pressure and thus will decrease the diffusive flow of fresh reactants to the hot zone, improving the deposition in colder areas. This explanation does not exclude other phenomena taking place at the same time as, for instance, the decrease of the sticking coefficient for the $\mathrm{TiC}$ molecules when temperature increases. This argument was successfully used by one of the authors [26] to model the LCVD of TiN films at high temperatures.

The curves shown in Fig. 4 were obtained by digitalizing the measured profiles. Only their central region is plotted, corresponding to the zone where the deposition of $\mathrm{TiC}$, and presumably of $\mathrm{SiC}$, have occurred. Outside this zone, concentric with it, a circular depression could be observed in the as-measured profiles which means that the substrate surface 
was etched, probably by the chlorine resulting from $\mathrm{TiCl}_{4}$ decomposition or by the combination of chlorine and hydrogen [27]. The depth of this etched zone increased with laser irradiance and interaction time, i.e. with temperature. Before reaching the zero level, the surface profiles still included the deposits of the titanium oxydes previously analyzed by XRD.

The thickness profiles were very useful in providing a means to investigate the kinetics of the TiC film growth because not only the evaluation of the total amount of deposited material was made possible, but also the surface temperature across each spot diameter could be estimated. The diameters of the TiC spots, taken from the thickness profiles, are shown in Fig. 5 as a function of the incident laser power for various irradiation times. They increase with laser power and interaction time up to a maximum value of $-6 \mathrm{~mm}$,

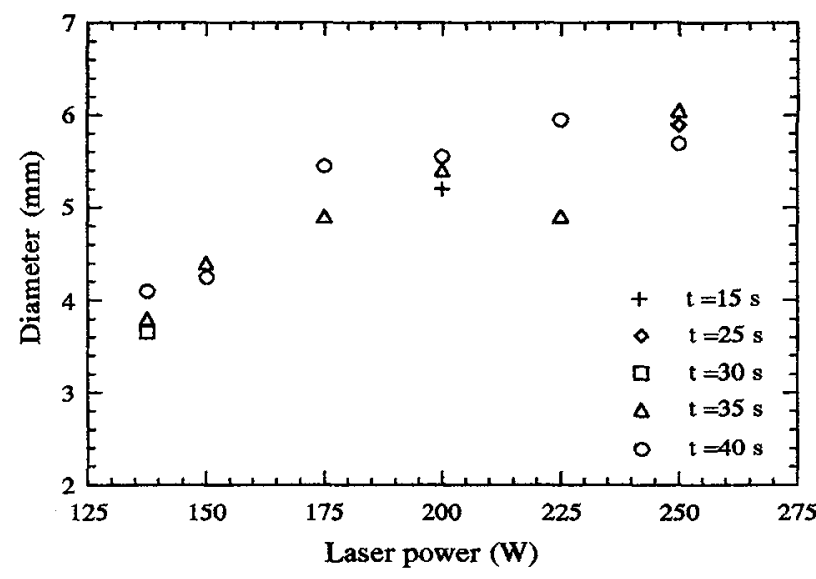

Fig. 5. - Influence of the incident laser power on the lateral extension of TiC films deposited by LCVD which is much smaller than the spot size of the laser beam at the substrate surface. This means that the threshold temperature for the chemical reaction is reached inside the gaussian energy distribution in the laser beam. Then, by assuming that the threshold temperature is $1173 \mathrm{~K} \mathrm{[28]} \mathrm{and} \mathrm{it} \mathrm{is} \mathrm{attained} \mathrm{at} \mathrm{the}$ edge of the TiC deposits, the surface temperature at the spot centre could be predicted for each pair of laser powerinteraction time values. This temperature was thus considered as the deposition temperature for the LCVD process. Although the method just described may look over simplified, we believe that it gives deposition temperatures very close to reality (see below).

Because the profiles are not perfectly symmetrical and their shape changes with increasing temperature, it becomes difficult to set a criteria for which is the best measure of the thickness. Therefore, it is more accurate to evaluate the apparent deposition rate for the TiC films in terms of the total mass of titanium carbide deposited per unit time, instead of the thickness of the profiles. Then, to obtain this total mass, we integrated the (2-d) experimental cross-sections of the thickness profiles over an angle $\varphi$ which describes the rotation of the profile around an axis perpendicular to the substrate. The results of the calculations are shown in Fig. 6 for different values of the processing parameters, where we used the bulk density of TiC, $4.93 \mathrm{g.cm}{ }^{-3}$. As it can be seen from this figute, there is a decrease in the deposited mass for the highest incident laser power at the longer irradiation times. The two arguments already given to explain the appearance of the volcanolike deposits may also be considered here to justify the smaller amount of material which is deposited at that laser power level.

Figure 7 illustrates an Arrhenius plot where the apparent deposition rate and the temperature are those evaluated above. The data were fitted by a single straight line using a least-squares method, yielding an apparent activation energy of $86 \mathrm{~kJ} /$ mole. The fact that only one straight line is needed to fit the data implies that only one mechanism is responsible for the the growth of the TiC layers. The apparent activation energy 


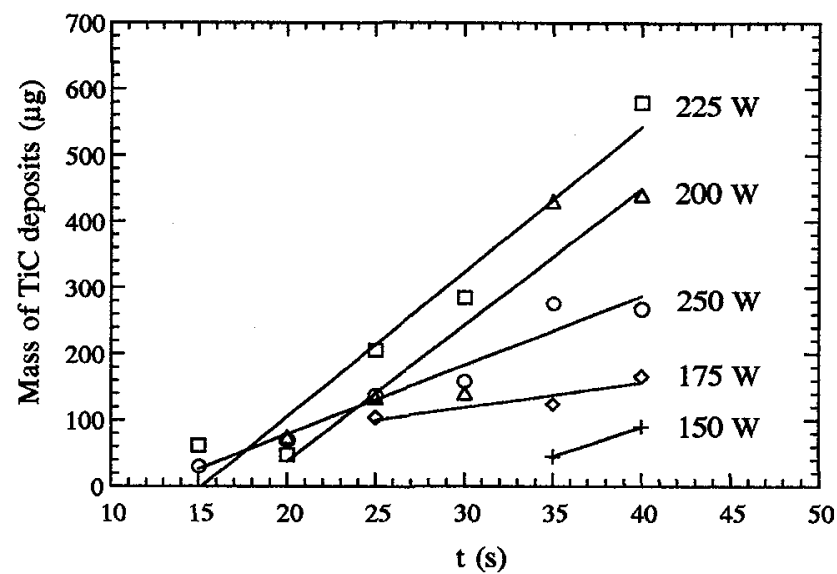

Fig. 6. - Influence of the irradiation time on the mass of the TiC films deposited at various laser powers

that we obtained is in very good agreement with results reported $[29,30]$ for CVD of TiC films grown from a $\mathrm{TiCl}_{4}+\mathrm{CH}_{4}+\mathrm{H}_{2}$ gas mixture at $\mathrm{T} \geq 950^{\circ} \mathrm{C}$. In this temperature range, Rossignol et al. [30] interpreted their results in terms of a mass transport control of the CVD process. This suggests that, in our experimental conditions, the kinetics of LCVD of TiC is also limited by the diffusion of the gaseous species into the localized chemical reaction zone.

Fig.7. - Effect of the temperature at the beam centre on the TiC deposition rate $\dot{m}(\mu \mathrm{g} / \mathrm{s}) ;$ Arrhenius plot.

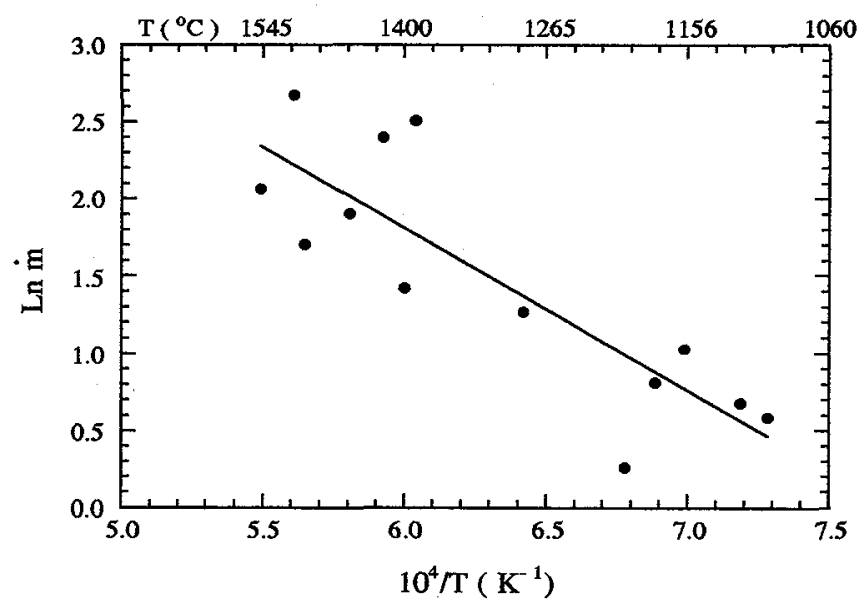

\section{4.- Conclusion}

In this work, we have investigated the thermal laser chemical vapour deposition of TiC films onto fused silica substrates. The films were grown at a constant pressure of the reactants using a $\mathrm{CW}$ TEM $00 \mathrm{CO}_{2}$ laser. The films obtained were polycrystalline and preferentially (200) oriented. We have shown that the growth conditions, i.e. the incident laser power and the irradiation time, influence the microstructure and the morphology of the deposits. The mass of $\mathrm{TiC}$ deposited per unit time and the deposition temperature range were determined from the thickness profiles measurements. Those two quantities were then represented in an Arrhenius plot, yielding an apparent activation energy for the LCVD process of 86 $\mathrm{kJ} /$ mole. By comparing this value with results reported in the literature, we concluded that under our deposition conditions the LCVD of TiC is controlled by mass transport. 


\section{5.- Acknowledgements}

The authors wish to acknowledge IST and INESC, from Lisboa, for the use of the SEM and profilometer facilities, respectively.

\section{6.- References}

[1] PIERSON H.O., Handbook of Chemical Vapor Deposition (Noyes Publications, N.J., 1992).

[2] ABE T., MURAKAMI Y., OBARA K., HIROKI S., NAKAMURA K., MIZÓGUCHI T., DOI A., INAGAWA K., J. Nucl. Mater. 133 (1985) 754.

[3] RIST O., MURRAY P.T., Mater. Lett. 10 (1991) 323.

[4] SUNDGREN J.-E., HENTZELL H.T.G., J. Vac. Sci. Technol. A4 (1986) 2259

[5] LYDTIN H., in Proc. of the 3rd Intern. Conf. on CVD, Ed. F.A. Glaski (Am. Nucl. Soc., Hinsdale, IL, 1972), p. 121 .

[6] Laser Processing and Diagnostics, Springer Series in Chem. Phys., Vol. 39, Ed. D. Bauerle (Springer, Berlin, 1984).

[7] MAZUMDER J., ALLEN S.D., in Proc. of the SPIE on Laser Applications in Materials Processing (1979), p. 73.

[8] ALLEN S.D., J. Appl. Phys. 52 (1981) 6501.

[9] UMEZAWA A., KIKUCHI K., SHIKATA N., J. Mech. Eng. Laboratory 45 (1991) 257.

[10] WESTBERG H., BOMAN M., CARLSSON J.-O., Thin Solid Films 218 (1992) 8.

[11] CONDE O., MARIANO J., SILVESTRE A.J., VILAR R., in Proc. of the 3rd European Conf. on Laser Treatment of Materials, vol. 1, Eds. H. W. Bergmann and R. Kupfer (Sprechsal, Coburg, 1990), p. 145.

[12] TOULOUKIAN Y.S., DEWITT D.P., Thermophysical Properties of Matter, vol. 8 (IFI/Plenum, N.Y., 1972).

[13] LUX B., HAUBNER R., in Proc. of the NATO ASI on Diamond and Diamond-like Films and Coatings, Series B, vol. 266, Eds. R.E. Clausing, L.L. Horton, J.C. Angus and P. Koidl (Plenum Press, N.Y., 1991), p. 579.

[14] TAYLOR P. R., PIRZADA S. A., in Plasma and Laser Processing of Materials, Ed. K. Upadhya (TMS, Warrendale, PA, 1991), p. 123.

[15] BAIK D.S., KIM M.S., CHUN J.S., in Proc. of the 9th Intern. Conf. on CVD (Electrochem. Soc., 1984), p. 745.

[16] YOON S.G., KIM H.G., CHUN J.S., J. Mater. Sci. 22 (1987) 2629.

[17] JANG D.H., CHUN J.S., Thin Solid Films 149 (1987) 95.

[18] CARLSSON J.-O., in Advanced Surface Coatings, Eds. D.S. Rickerby and A. Mathews (Blackie \& Son, N.Y., 1991), p. 162.

[19] SILVESTRE A.J., CONDE O., VILAR R., JEANDIN M., to be published in J. Mater. Sci.

[20] MOYLAN C.R., BAUM T.H., JONES C.R., Appl. Phys. A40 (1986) 1.

[21] CONDE O., FERREIRA M.L.G., HOCHHOLDINGER P., SILVESTRE A.J., VILAR R., App1. Surf. Sci. 54 (1992) 130.

[22] HERMAN I.P., HYDE R.A., MCWILLIAMS B.M., WEISBERG A.H., WOOD L.L., Mater. Res. Soc. Symp. Proc. 17 (1983) 9.

[23] ALLEN S.D., JAN R.Y., EDWARDS R.H., MAZUK S.M., VERNON S.D., SPIE 459 (1984) 42.

[24] SKOUBY D.C., JENSEN K.F., J. Appl. Phys. 63 (1988) 198.

[25] KAR A., AZER M.N., MAZUMDER J., J. Appl. Phys. 69 (1991) 757.

[26] CONDE O., KAR A., MAZUMDER J., J. Appl. Phys. 72 (1992) 754.

[27] KUBASCHEWSKI O., ALCOCK C.B., Metallurgical Thermochemistry (Pergamon Press, Oxford, 1979), p. 215.

[28] BOVING H.J., HINTERMANN H.E., Tribology Intern. 23 (1990) 129.

[29] HARA A., YAMAMOTO T., TOBIOKA M., High Temp.-High Pressures 10 (1978) 309.

[30] ROSSIGNOL J.Y., LANGLAIS F., NASLAIN R., in Proc. of the 9th Intern. Conf. on CVD (Electrochem. Soc., 1984), p. 596. 